\section{OS SAMBAS DAS GEOGRAFIAS DE SAMPA: CRIACCÕES MÚLTIPLAS DE ENREDOS, ADERECOS, ALEGORIAS E ENROSCOS}

DOZENA, Alessandro. A geografia do samba na cidade de São Paulo. São Paulo: Fundação Polisaber, 2011. $264 \mathrm{p}$ ISBN 856-491-5008

Valéria Cazetta

O livro "A geografia do samba na cidade de São Paulo", título homônimo à tese de doutorado (de Alessandro Dozena) se originou daí. A investigação realizada por este autor só foi possível em decorrência do seu engajamento nos caminhos da pesquisa etnográfica que, diga-se de passagem, não é tarefa fácil, porque requer do pesquisador certa sensibilidade poética além de um mergulho na temática de estudo gestada outrora e agora, no decorrer da vida em suas múltiplas e inter-relacionadas dimensões. "A arte de construir um problema é muito importante: inventa-se um problema, uma posição de problema, antes de encontrar a solução" (DELEUZE; PARNET, 1998, p.02). Ou dito de outra maneira: "é o olhar que botamos sobre as coisas que, de certa maneira, as constitui. São os olhares que colocamos sobre as coisas que criam os problemas do mundo. Em outras palavras, não há problemas em si [...], pairando numa exterioridade, inertes num grande depósito à sombra, à espera de serem, antes, encontrados pela luz que lançamos sobre eles e, depois, solucionados pela razão". (VEIGA-NETO, 2007, p.30). Ou escrito de outro modo: "Pretendi deixar dito também de como a visão - de como o modo de ver, o ponto de vista - altera a realidade, construindo-a. Uma casa não é construída apenas com pedras, cimento, etc. O modo de olhar de um homem também a constrói. O modo de olhar dá o aspecto à realidade" (LISPECTOR, 1984, p.416).

Embora Alessandro não mencione explicitamente ao longo do livro seu itinerário pela etnografia, à medida que "experimentamos" o livro por meio dos seus escritos notamos nas suas entrelinhas e, por conseguinte, em seus silenciamentos, o intercâmbio do autor entre acadêmicos
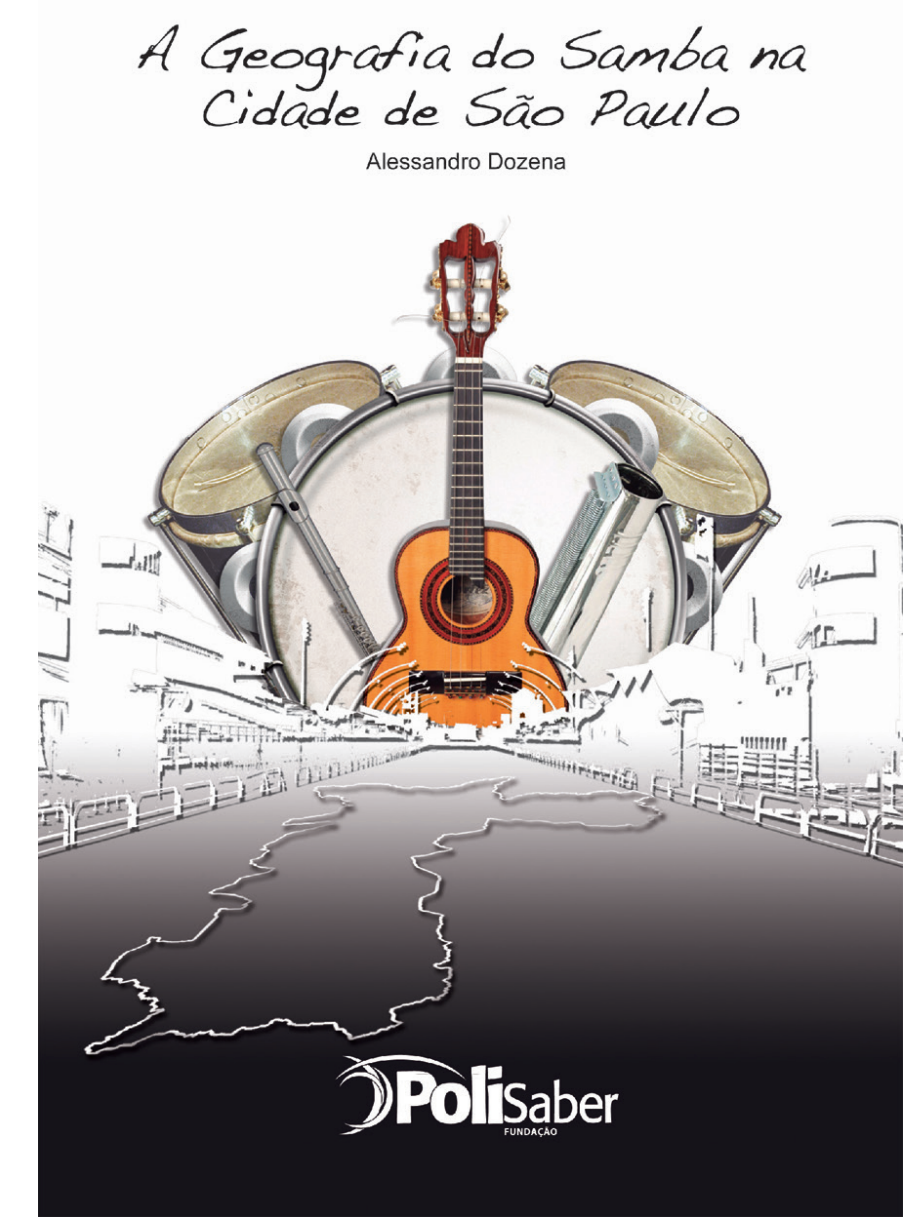

e populares (as entrevistas com os sambistas foram realizadas em vários locais de São Paulo no período compreendido entre 2006 a 2009), como bem lembrou Osvaldinho da Cuíca na Apresentação do livro. Este fato possibilitou ao autor tanto analisar as territorialidades do samba na tessitura da capital paulista quanto verificar 1 Docente da Escola de Artes, Ciências e Humanidades (EACH) da Universidade de São Paulo (USP). vcazetta@usp.br.
\Avenida Arlindo Béttio, 1000, Ermelino Matarazzo. 03828-000. São Paulo, SP. 
onde e como o samba se manifesta, isto é, desde sua transformação e deslocamento para as diferentes regiões da Pauliceia (em alusão à "Paulicéia Desvairada" de Mário de Andrade) até algumas ações de demarcação, apropriação, controle e experiências territoriais exercidas pelos sambistas.

Antes de apontar o que o leitor encontrará em cada um dos capítulos, bem como as surpresas que o esperam, convém destacar que Alessandro diferencia logo no início do livro que o samba ultrapassa um dado estilo musical, constituindo-se numa dimensão mais ampla que a do Carnaval - festa carnavalesca que foi envolvida pelo espetáculo televisivo para usar as palavras do autor -, gestando novas relações sociais por meio de uma movimentação específica que ocorre nos "territórios do samba" (rodas de samba, blocos carnavalescos, movimentos de samba e eventos que acontecem no decorrer do ano nas quadras das escolas de samba). Para tanto, o autor lança mão do procedimento da periodização - proposto por Milton Santos - para evidenciar as relações dialéticas entre o samba e o carnaval paulistano no contexto espacial e temporal brasileiro.

A seguir apresentarei ao leitor cada um dos capítulos do livro.

No de número 1, "O samba na construção do processo de urbanização da cidade de São Paulo", o autor analisa o processo de formação dos primeiros cordões e escolas de samba, levando em consideração o contexto do núcleo urbano paulistano original para, em seguida, compreender e discorrer sobre sua dispersão rumo às demais regiões da cidade. De modo cauteloso o autor justapõe a esta análise os atravessamentos culturais sofridos pelos sambistas e, ao lançar mão da linguagem cartográfica, produz um conjunto de sete mapas temáticos (apresentados ao final do livro - páginas 249 a 255) acerca das dinâmicas territoriais do samba paulistano. Nestes mapas são abordados: a dispersão dos sambistas em São Paulo nos períodos de 1914 a 1969 e de 1970 a 1992; a expansão da área urbanizada em São Paulo; as escolas de samba paulistanas em atividade, bem como a cronologia de suas fundações; a distribuição das escolas de samba ativas por classes econômicas; a proveniência dos associados da escola de samba Unidos do Peruche; o limite hipotético do Bixiga e o território que é usado, de fato, no bairro mencionado.

Aqui abro um parêntese. Para explicar o que entendo acerca dos "atravessamentos culturais sofridos pelos sambistas" mencionados por mim acima; convém esclarecer para o leitor que isso remete tanto às festividades negras realizadas em contextos urbano e/ou rural, incluindo aquelas de cunho religioso, tais como: o candomblé, a umbanda e o catolicismo, quanto às distintas sonoridades da música popular brasileira. Como bem argumentou Dozena, "o samba ouvido e entoado na capital paulista tem suas origens nos batuques que eram realizados nas senzalas e nos terreiros, onde desde o período colonial brasileiro, os tambores são percutidos em rituais religiosos, sejam eles católicos ou não. $\mathrm{O}$ mesmo se aplica às rodas de capoeira e de tiririca [...]" (p.29). Por sua vez, nas fazendas escravistas, as festas de terreiro eram aceitas somente nas folgas semanais e feriados - únicos momentos nos quais os escravos reuniam-se, porque na maioria das vezes eles trabalhavam separadamente.

Voltando... Outro aspecto para o qual o autor dará destaque no livro diz respeito à importância das festividades negras que aconteciam nas áreas rurais e que continuaram a ocorrer na cidade (no primeiro quartel do século XX a partir da formação dos cordões carnavalescos) quando a capital paulista concentrou um grande contingente de negros oriundos das fazendas de café do interior paulista (em decorrência da Abolição da Escravatura), que estavam em busca de trabalho livre. Com a hibridização do samba rural paulista houvera uma "atualização nos ritmos e instrumentos utilizados nos rituais religiosos e/ou festivos" 
(p.33) que, por sua vez, afetou sobremaneira a cultura afro-brasileira. Até os dias atuais a cidade de São Paulo acabou por se configurar em um lugar composto por tantos outros lugares e com lógicas distintas, em decorrência dos fragmentos da cultura afro-brasileira que foram convergidos para a capital paulista. Isso resultou nas escolas de samba e nas rodas de samba que acontecem nos bairros marginais, lembrando que as primeiras foram instituídas quando "da incorporação da organização europeia dos desfiles carnavalescos, representados pelos corsos" (p.34-35).

O carnaval paulistano estava assentado até o começo do século XX no modelo de corsos e estava reservada aos negros e brancos pobres somente uma possibilidade: assistir o desfile a distância. Como forma de inserção social foram criadas as primeiras escolas de samba e, por conseguinte, houvera a legitimação da prática das religiões da Umbanda e do Candomblé que, com seus batuques, irão constituir os alicerces rítmicos do samba e suas especificidades, seguindo a concepção africana de rítmica solista.

Ainda neste mesmo capítulo Dozena caminhará pelas "raízes territoriais" do samba paulistano, destacando as mudanças em sua dinâmica que incorporará elementos da ruralidade e do urbano contexto no qual ocorrerá sua expansão para além das margens do rio Tietê, "coincidindo" com a fundação das escolas de samba paulistanas. O autor também abordará as geografias do bairro no "mundo do samba", montando o emaranhado quebra-cabeças teórico do samba a partir das relações de pertencimento das pessoas que são da "quebrada", do "pedaço" e "forasteiros". Para tanto, o autor realiza sua análise empírica no Bexiga e no Parque do Peruche.

No capítulo dois, "A dimensão cultural do samba", Dozena dialoga com autores da Escola de Frankfurt (Adorno e Horkheimer), dos Estudos Culturais (Raymond Willians), da Filosofia (Michael Foucault) e da Geografia (Rogério Haesbaert, Milton Santos) entre outros, para advogar em prol de que na capital paulista as práticas de samba configuram "contraespaços" nas ordens sociais majoritárias. Ou seja, as "práticas sociais e discursos dos sambistas surgem como uma contrafinalidade" (p.137). Aqui o autor é novamente cuidadoso e lembra o leitor da importância "de evitar uma visão dual ao se trabalhar dialeticamente com a noção de contrafinalidade" (p.137), porque "o que é racional pode momentaneamente tornar-se irracional, ou seja, em alguns casos pode haver a coexistência dialética entre racionalidade e irracionalidade, ao mesmo tempo, não havendo uma racionalidade paralela em virtude de uma estar entranhada na outra" (p.138).

A noção de contrafinalidade proposta por Dozena encontra-se situada dentro do processo social e não fora dele. E o autor ainda realiza um contraponto interessante ao entendimento bastante comum que temos do samba, isto é, de que ele se encerraria no carnaval espetáculo. Para além disso, o autor apontou em seu estudo a existência de sociabilidades outras na cidade de São Paulo, atravessadas pelo samba afinal: "nem todas as instâncias da vida social e simbólica se transformam em mercadorias, embora haja uma forte tendência dominante para tal", porque "é na prática cotidiana dos sambistas que surgem as possibilidades de usos territoriais não vislumbrados pela racionalidade hegemônica. Neste sentido, o samba aponta para um projeto civilizacional cunhado a partir dos lugares" (p.143).

Como se estivesse a fazer um trabalho arqueológico, Dozena escava as letras de um dos principais sambistas paulistanos, Adoniran Barbosa, as quais estavam alicerçadas no tempo da cultura oral e da conversa (e não do "letramento"), ou seja, na contramão das práticas sociais "homogeneizadoras", cujos discursos enunciavam a capital paulista como a "locomotiva da federação". Dozena também "samba" seus escritos no contexto do surgimento dos Disc Jockeys (DJs), do 
rap, do funk e do hip-hop - que são outras musicalidades apropriadas pelos negros brasileiros a partir de contextos-periféricos-geográficosespecíficos.

Neste capítulo o autor também aborda a papel da corporeidade na conformação de territorializações urbanas. Se por um lado a corporeidade delimita estratégias "de distinção e fixação de estilos demarcadores de sociabilidade, enunciando territórios simbólicos precisos e modelos de indivíduos singulares [...] que nas cidades exercem apropriações particulares" (p.159), por outro, o corpo traz as marcas da cultura na qual está inserido, isto é, criam-se as "subjetivações territoriais" - fortemente marcadas nas músicas, nas melodias, nos ritmos, nas danças, nas letras e nas harmonias.

Segundo o autor a corporalidade é o que possibilita a recriação de "territórios originais" que atendem não somente às aspirações de sobrevivência da coletividade dos sambistas, mas também às suas especificidades culturais, porque "a experiência corporal fixa o território na existência, na medida em que o corpo é o ser no território" (p.161).

Ao abordar os movimentos de samba na cidade de São Paulo, Dozena retoma de forma mais contundente a ideia de gêneros de vida, do geógrafo francês Vidal de La Blache, e afirma que desde a década de 1990, os movimentos de samba na cidade de São Paulo têm procurado resgatar as "raízes" do samba. Para o autor "o estudo desses movimentos pode revelar aspectos importantes com relação ao cotidiano e gêneros de vida da comunidade envolvida, bem como as apropriações territoriais que permitem as conquistas de maiores direitos na cidade" (p.165). Dentre os movimentos de samba destacados pelo autor tem-se: Samba da Vela, Samba da Laje, Rua do Samba Paulista, Samba do Cafofo, Samba do Olaria, Samba da Maria Cursi, Comunidade Morro das Pedras, Samba D'Elas, Moleque Travesso,
Samba de Fato, Só quem é negreiro, Samba de Todos os Anos, Samba de São Matheus, Samba Terra Brasileira e Samba do Baú, além de muitas outras rodas de samba que surgiram, seja em decorrência "de não haver mais abertura para o contato com as composições mais antigas dentro das escolas de samba" (p.167), seja como uma "prática de resistência à mercantilice da vida e dos modos de existência" (p.175).

No capítulo três, "A dimensão política e econômica do 'mundo do samba"', o autor "mapeou" o uso político do território, compreendendo a utilização e organização dos "territórios do samba". Para tanto escarafunchou as negociações presentes no samba paulistano a partir de depoimentos de sambistas, diretores e presidentes de escolas de samba, organizadores de rodas de samba, presidentes da União das Escolas de Samba Paulistanas (Uesp) e da Liga Independente das Escolas de Samba (LigaSP). Outro flanco sobre o qual o autor se debruçou foi a força de trabalho empregada nas escolas de samba ao longo do ano todo. Para que o desfile das escolas de samba aconteça anualmente é necessário um trabalho intenso realizado para e pelas escolas, envolvendo desde a contratação de pessoas para a confecção de fantasias até a de um carnavalesco que, por sua vez, possui uma equipe remunerada. E "quanto maior a escola de samba, maior é a complexidade das relações de trabalho" (p.204). Para organizarem o desfile anual, as escolas de samba recebem um incentivo da Prefeitura Municipal de São Paulo, além de recursos provenientes do patrocínio de colaboradores, de eventos ao longo do ano, de shows da bateria e das passistas, da venda de artigos da escola, da bilheteria dos desfiles, dos direitos de transmissão de imagens pela Rede Globo, das leis de incentivo aos projetos culturais e sociais, etc.

Dozena irá explorar a partir de depoimentos das pessoas envolvidas com o "mundo do samba", as novas dinâmicas socioespaciais oriundas do carnaval nos últimos dez anos, porque "há uma cadeia produtiva 
voltada ao desfile carnavalesco, que passa pela compra do material para a fabricação dos protótipos das fantasias, pela contratação do carnavalesco e da equipe de costureiros, pelos chapeleiros, aderecistas, sapateiros" (p.196), além dos ateliês espalhados pela cidade de São Paulo que também atendem às escolas de samba. Ou seja, o carnaval é um acontecimento que envolve uma organização bastante complexa, sendo primordiais as estratégias de gerenciamento do dinheiro disponível para os investimentos. Um exemplo bastante interessante e que de acordo com Dozena possui, nos dias de hoje, uma nova realidade diz respeito à contratação de mão de obra proveniente da cidade amazonense de Parintins, onde se realiza anualmente o Festival Folclórico de Parintins, para a confecção dos carros alegóricos - importante elemento do desfile. Para Dozena a Festa do Boi de Parintins mereceria ser estudada pelos geógrafos, por tratar-se de um elemento cultural que está a grafar dinâmicas próprias na geografia amazonense e do Brasil.

Da construção da "Fábrica dos Sonhos" - anunciada pela Prefeitura Municipal de São Paulo em og/01/2008 - o autor abordou a estratégia logística do projeto na produção de um território específico para a preparação do desfile carnavalesco, destacando que provavelmente o fato de algumas quadras das escolas se localizarem nas adjacências do Sambódromo do Anhembi, possa ter influenciado a implantação do Sambódromo na região norte da capital paulista, considerando-se que muitas quadras já se localizavam aí antes de 1991 - ano de fundação do Sambódromo. Ao comparar a "Cidade do Samba" - construída para abrigar os barracões das escolas de samba pertencentes ao Grupo Especial no Rio de Janeiro e cujas atividades foram iniciadas em 2005 - com a "Fábrica dos Sonhos", Dozena afirma que a implantação da primeira consistiv em uma atitude puramente gerencial e empresarial da prefeitura fluminense em parceria com a Liga das Escolas de Samba
(Liesa). No caso da segunda, há uma preocupação da prefeitura paulistana com o turismo, mas também com a geração de empregos e a realização de shows, eventos culturais e a instalação do "Memorial do Samba".

No último capítulo, "'O samba pede passagem': as perspectivas para estudos vindouros", o autor aponta possibilidades de estudos outros acerca do samba, entendendo-o não somente como um gênero musical, mas como um modo de pensar, de sentir e de construir territorializações específicas na cidade, ou seja, o samba surge como "sinônimo de fonte inspiradora, de ritmicidade, de ludicidade, de poder criativo e libertário, de 'exercício religioso' para alguns e de atividade poética e revolucionária para outros (ainda que esteja envolto em uma estrutura social hierarquizada)" (p.216). Se não fosse por meio de sua sensibilidade poética, o autor deste livro não teria conseguido transcender a escala cartográfica em seu estudo acerca da tríade sambistas-territorialidades-geografias em sua pesquisa. Utilizo a tríade no plural por pensar que Dozena amplia sua reflexão para além dos binarismos que às vezes cometemos desapercebidamente.

Em verso, em prosa, em ditos e escritos sobre o samba, em encontros entre a oralidade e o letramento. Alessandro provavelmente desacostumará no leitor (atento) aquele jeito único de pensar e conceber o samba em Sampa. As maneiras como ele nos apresenta a Pauliceia por meio das territorialidades atravessadas pelo samba, nos faz "sambar" literalmente, nos pega no contratempo, nos ejeta para outras cidades de São Paulo que extrapolam aquela dos limites políticos administrativos oficiais. São várias as versões apresentadas por Dozena e nenhuma delas é mais ou menos verdadeira, mas, sim, múltiplas e impermanentes. 
Este autor nos contou sobre a cidade do samba, outrora Pauliceia, outrora São Paulo, agora e futuramente "Fábrica dos Sonhos". Ítalo Calvino inutilmente descreveu a cidade de Zaíra - como ele mesmo afirmou -, mas inventou uma Zaíra que coubesse em seus sonhos, em sua vida, em suas imaginações geográficas. Inventou uma cosmologia urbana para Zaíra ao afirmar que a cidade é feita "das relações entre as medidas de seu espaço e os acontecimentos do passado: a distância do solo até um lampião e os pés pendentes de um usurpador enforcado; o fio esticado do lampião à balaustrada em frente e os festões que empavesavam o percurso do cortejo nupcial da rainha; a altura daquela balaustrada e o salto do adúltero que foge de madrugada; a inclinação de um canal que escoa a água das chuvas e o passo majestoso de um gato que se introduz numa janela; a linha de tiro da canhoneira que surge inesperadamente atrás do cabo e a bomba que destrói o canal, os rasgos nas redes de pesca e os três velhos remendando as redes que, sentados no molhe, contam pela milésima vez a história da canhoneira do usurpador, que dizem ser o filho ilegítimo da rainha, abandonado de cueiro ali sobre o molhe. A cidade se embebe como uma esponja dessa onda que reflui das recordações e se dilata. Uma descrição de Zaíra como é atualmente deveria conter todo o passado de Zaíra. Mas a cidade não conta o seu passado, ela o contém como as linhas da mão, escrito nos ângulos das ruas, nas grades das janelas, nos corrimões das escadas, nas antenas dos pára-raios, nos mastros das bandeiras, cada segmento riscado por arranhões, entalhes, esfoladuras" (p.14) e os sambas que pedem passagem. Não vemos o samba. Ele simplesmente acontece. Sentir, mapear, fotografar o samba não é suficiente. Por isso inventamos cotidianamente as linguagens: para capturar o samba, mas o samba passa, nos atravessa, nos desloca. E por isso também decidi fazer outra resenha acerca deste livro outrora resenhado por Thiago Rodrigues Gonçalves nessa mesma revista, porque pretendi deixar dito também que uma casa, o samba, a cidade, não são construídos apenas com pedras, cimento, etc. O modo de olhar de um homem também os constróem. Tenho aprendido com Clarice Lispector (em "A Descoberto do Mundo"), com Alessandro Dozena (em "A geografia do Samba na cidade de São Paulo") e com Ítalo Calvino (em "Cidades invisíveis") a inventar memórias, cidades, gentes, geografias e "sambas" para "sampar".

\section{REFERÊNCIAS}

CALVINO, Ítalo. As cidades invisíveis. Tradução de Diogo Mainardi. 2Ed. São Paulo: Companhia das Letras, 1990.

DELEUZE, Gilles; PARNET, Claire. Diálogos. Trad. Eloisa Araújo Ribeiro. São Paulo: Editora Escuta, 1998.

GONÇALVES, Thiago Rodrigues. A geografia do samba na cidade de São Paulo (Resenha). Geograficidade, v.1, n.2, p. 67-68, 2012.

LISPECTOR, Clarice. A descoberta do mundo. Rio de Janeiro: Nova Fronteira, 1984.

VEIGA-NETO, Alfredo. Olhares... In: COSTA, Marisa Vorraber (Org.). 3. ed. Caminhos Investigativos I: novos olhares na pesquisa em educação. Rio de Janeiro: Lamparina, 2007. p. 23-38. 